\title{
Quantifying Differences in Health Care Consumption for the Management of Multiple Sclerosis Within Privately and Publicly Insured Health Care Programs
}

\author{
Terrie Livingston, PharmD; Monica Fay, PharmD, MBA; Ravi lyer, PhD; \\ Wendy Wells, PharmD; and Michael W. Pill, PharmD
}

\begin{abstract}
BACKGROUND: Multiple sclerosis (MS) is a chronic and debilitating disease of the central nervous system that affects more than 570,000 persons in the United States and 2.3 million worldwide. Since most individuals experience initial symptoms between the ages of 20 and 40 years, MS can have a significant effect on health care consumption, quality of life, productivity, and employment over the long-term disease course. Opportunities exist to better understand how benefit design and other nonclinical factors can affect health care delivery and associated costs.
\end{abstract}

OBJECTIVE: To observe and report variances in health care consumed for the treatment of MS in patients enrolled in privately (commercial) and publicly (Medicaid) funded health insurance programs.

METHODS: In a retrospective analysis using Havas Gemini's proprietary MS Benchmarks Disease-Modeling Process and IMS LifeLink Health Plan Claims and Longitudinal Prescriptions databases, integrated medical and pharmacy claims data were analyzed to select patients with a diagnosis of MS during the 2012 calendar year. Comorbidities were determined using ICD-9-CM codes present on medical claims. Prescription drug use was evaluated by pharmacy claims and drug-specific billing codes.

RESULTS: 19,984 patients with MS were identified-18,269 from commercial payers and 1,715 from Medicaid. Although total annual costs related to the care of MS for the groups reflected a relatively small difference $(\$ 31,107$ commercial; \$33,344 Medicaid), costs associated with specific service categories varied greatly. Pharmacy costs were considerably less in the Medicaid group; however, inpatient and emergency room costs were as much as 5 times higher. Overall use of disease-modifying treatments (DMTs) in the Medicaid group was seen in $32.5 \%$ of patients and $52.1 \%$ in the commercial patient group. Thus, lower pharmacy costs in the Medicaid group were possibly related to lesser use of DMTs among that group of patients.

CONCLUSIONS: This analysis illustrates that notable variances exist in consumption of health care resources between patients enrolled in privately and publicly funded health care programs. These variances may have additional implications relating to outcomes specific to MS.

J Manag Care Spec Pharm. 2016;22(12):1385-91

Copyright $\odot 2016$, Academy of Managed Care Pharmacy. All rights reserved.

\section{What is already known about this subject}

A person with multiple sclerosis (MS) relies on health care to provide medical care, prescription drugs, rehabilitation services, and allied health needs.

The availability of resources and drug therapies may have profound implications on disease progression, health care utilization and costs, productivity, and quality of life.
Medicaid coverage, compared with other insurance types such as commercial insurance, has been associated with poorer access to preventive, acute, and follow-up care.

\section{What this study adds}

This study provides a source of notable differences in health care utilization and outcomes between commercially and publicly insured MS patients.

When comparing publicly (Medicaid) and commercially insured MS patients, Medicaid patients had overall lower use of diseasemodifying treatments and reflected higher rates of many conditions related to MS, such as gait abnormalities, dysesthesia, dizziness, and urinary incontinence, as well as other comorbid conditions such as asthma, diabetes, and hypertension.

This study found that Medicaid-insured patients with MS had inpatient and emergency room costs that were as much as 5 times higher than MS patients who were commercially insured.

$\mathrm{M}$ ultiple sclerosis (MS) is a chronic and debilitating disease of the central nervous system that is characterized by inflammation, demyelination, scarring, and neuronal loss that causes disruption in the ability of nerves to conduct electrical impulses to and from the brain., ${ }^{1,2}$ MS is believed to be autoimmune in nature and may present as relapsing-remitting or progressive. ${ }^{1,3,4}$ MS affects approximately 570,000 persons in the United States and 2.3 million persons worldwide. ${ }^{5-8}$ Most individuals experience initial symptoms between the ages of 20 and 40 years. ${ }^{4,6,9}$ The most common symptoms of MS are fatigue, reduced mobility, bowel and bladder disturbances, diminished cognitive function, pain, sensory loss, and depression. ${ }^{2,4}$ The majority of people with MS experience chronic progression that may become incapacitating and require profound lifestyle adjustments. ${ }^{3,10} \mathrm{Up}$ to $93 \%$ of people with MS report some degree of functional impairment contributing to mobility problems (impaired walking ability, loss of balance, weakness, and spasticity).11,12 A 2013 study by Agarwal et al. found that $58 \%$ of people with MS experienced these mobility problems within the first year after diagnosis. ${ }^{11}$ Since most people with MS have a normal lifespan despite 
disability, MS may impose a significant effect on health care consumption, quality of life, productivity, and employment over the long-term disease course. , $^{6,12-14}$

The availability of health care resources and drug therapies to MS patients may have profound implications on disease progression, health care utilization and costs, productivity, and quality of life. The purpose of this study was to observe and report variances in health care consumed for the treatment of MS in patients enrolled in privately (commercial) and publicly (Medicaid) funded health insurance programs.

\section{Methods}

\section{Study Design}

This study presents the results of a retrospective claims-based analysis using Havas Gemini's proprietary MS Benchmarks Disease-Modeling Process on data from the IMS LifeLink Health Plan Claims and Longitudinal Prescriptions databases during the 2012 calendar year. At the time these analyses were conducted, the IMS LifeLink Health Plan Claims Database contained data from approximately 60 million de-identified patients in over 100 private (commercial) and public (Medicare and Medicaid) managed care plans across the United States. Additional data used in these analyses included patient characteristics such as geographical region, age, gender, and payer type. Because of the broad reach of this data, patients were similar to the national insured population in terms of age and gender.

Gemini's proprietary disease model follows a standardized format and template to make understanding the disease process and data outputs easier. The disease model includes the following:

1. The criteria for eligibility, inclusion, and exclusion criteria for patients being included in the analysis are defined and documented.

2. Other criteria such as definitions of enrollment and history of disease are documented where relevant for a given disease process.

3. Demographic markers (age, gender, product type, payer, region, and physician specialty) are documented and defined.

4. Clinical markers, the range of associated disease processes, complications, and comorbidities that are key to a particular disease are documented, along with the relevant ICD-9-CM (International Classification of Diseases, Ninth Revision, Clinical Modification) codes.

5. Pharmacotherapy markers are identified, listing all drug categories, drug classes, and generic names of those drugs that are related to the disease process of interest and/or have been requested specifically. Where IMS LifeLink is the source of the dataset, the Healthcare Common Procedure Coding System codes and General Product Identifier codes that comprise these drugs are listed and documented.
6. Ancillary Service Markers are documented. These represent services of interest that are directly or indirectly associated with the underlying disease and are the variables reported in the analysis. The relevant procedure codes (Current Procedural Terminology, 4th edition, primarily, but revenue code when appropriate) are detailed and documented.

7. Definitions of the terms used throughout the analysis and results are listed and defined.

When put together, this MS-specific disease model provided the framework on which the entire analysis in this article was based. The model gives the data user the ability to see how, why, and what went into the analysis and, if desired, the ability to recreate the analysis, since all of the terminology, data elements, variables, and definitions are provided and documented. (For a summary of the MS-specific disease model, see the Appendix, available in online article.)

Charges and use of medical services and prescription drugs were identified and captured using the Episode Treatment Groups (ETG) software and were collected specifically for ETG 315100 (Multiple Sclerosis) during the study period of January 1, 2012-December 31, 2012. Episodes were grouped by several criteria, including demographics, benefit/plan design, presence of specific medical conditions, and use of pharmacotherapy. Economic data were broken down by the service category: inpatient and outpatient (ancillary, facility, management, and surgical); emergency room (ER); and pharmacy, depicting at which point in the health care continuum the service was received. All costs presented in this analysis represent dollar amounts of charges submitted or billed by a practitioner or institution to the health plan or insurer for payment.

Patients were selected for inclusion if they were aged 18 years or older, had at least 1 ICD-9-CM code for MS (340.xx) and were continuously enrolled during the 2012 calendar year. Patients were divided into 2 cohorts: patients with Medicaid coverage and patients with commercial insurance coverage. Patients were excluded if they did not have complete eligibility during the study period (i.e., less than 12 months of coverage) or were missing age, gender, or benefit design data.

\section{Results}

In 2012, 19,984 patients with MS were identified-1,715 from Medicaid plans and 18,269 from commercial plans. Patients in the Medicaid group represented a younger group (aged 44.4 years vs. 48.8 years in the commercial group) with a slightly higher female population. Patients under 40 comprised a visibly higher percentage of the Medicaid group (36.3\% vs. 20.5\%; Table 1).

Overall annual cost differences related to MS care were relatively small between the commercial and Medicaid groups $(\$ 31,107$ vs. $\$ 33,344)$. However, there were notable contrasts in the prevalence of a select group of medical conditions related to MS, as well as common chronic medical conditions between 


\begin{tabular}{|c|c|c|}
\hline & $\begin{array}{l}\text { Medicaid } \\
\text { n (\%) }\end{array}$ & $\begin{array}{c}\text { Commercial } \\
\text { n (\%) }\end{array}$ \\
\hline Overall, $\mathbf{n}$ & 1,715 & 18,269 \\
\hline Mean age years $[S D]^{a}$ & 44.4 [12.3] & $48.8 \quad[11.2]$ \\
\hline \multicolumn{3}{|l|}{ Age group (years) } \\
\hline $18-29$ & $206(12.0)$ & (5.3) \\
\hline $30-39$ & $416 \quad(24.3)$ & $2,782 \quad(15.2)$ \\
\hline $40-49$ & 512 (29.9) & $5,241 \quad(28.7)$ \\
\hline $50-64$ & $493(28.7)$ & $8,368 \quad(45.8)$ \\
\hline $65+$ & $88 \quad(5.1)$ & $911 \quad(5.0)$ \\
\hline \multicolumn{3}{|l|}{ Genderb } \\
\hline Female & $1,398 \quad(81.5)$ & $14,029 \quad(76.8)$ \\
\hline Male & $317 \quad(18.5)$ & $4,240 \quad(23.2)$ \\
\hline \multicolumn{3}{|c|}{$\begin{array}{l}\text { aP value between the } 2 \text { average age groups was }<0.001 \text {. } \\
\text { bP value between the } 2 \text { genders was }<0.001 \text {, which was determined using Pearson's } \\
\text { chi-square test. } \\
S D=\text { standard deviation. }\end{array}$} \\
\hline
\end{tabular}

the 2 groups, with Medicaid patients reflecting higher rates of many conditions related to MS, such as gait abnormalities (17.3\% compared with $10.4 \%$ ), dysesthesia (21.9\% compared with $17.9 \%$ ), dizziness (14.6\% compared with 9.2\%), and urinary incontinence (16.0\% compared with 5.8\%). In addition, other chronic (or comorbid) conditions, including asthma, chronic obstructive pulmonary disease, diabetes, and hypertension, were higher in the Medicaid group. Almost none of the conditions observed were more prevalent in the commercial group (Tables 2 and 3).

Although total annual costs related to the care of MS for the groups reflected a relatively small difference, charges associated with specific service categories varied greatly (Table 4). Pharmacy charges were the major cost driver in both populations, although costs were considerably less in the Medicaid group compared with the commercial group (62.5\% vs $78.2 \%$ ). However, inpatient and ER charges were as much as 5 times higher in the Medicaid group. The higher ER and inpatient charges in the Medicaid group may be attributed to a greater percentage of the population having single and multiple ER visits than the commercial population (21.5\% vs. $6.7 \%)$ and a greater percentage of single and multiple inpatient admissions than the commercial population (6.9\% vs. $1.6 \%$; Table 5 ). While the percentage of patients having admissions was much higher in the Medicaid group compared with the commercial group, the average number of admissions per year between groups was similar (1.3 vs. 1.4). The Medicaid patients had a lower average length of stay, compared with the commercially insured patient cohort (8.3 vs. 12.5 days). These data suggest that Medicaid patients used ER and inpatient care at a higher rate than commercial patients and that the factors driving costs were related more to the volume of services required by the Medicaid patients.

\section{TABLE 2 Prevalence of Conditions of Interest}

\begin{tabular}{l|c|c|c}
\hline & $\begin{array}{c}\text { Medicaid } \\
\mathbf{n}(\boldsymbol{\%})\end{array}$ & $\begin{array}{c}\text { Commercial } \\
\mathbf{n}(\boldsymbol{\%})\end{array}$ & $\boldsymbol{P ~ V a l u e ~}^{\mathbf{a}}$ \\
\hline Overall, $\mathbf{n}$ & $\mathbf{1 , 7 1 5}$ & $\mathbf{1 8 , 2 6 9}$ & \\
\hline Hypertension & $612(35.7)$ & $5,523(30.2)$ & $<0.001$ \\
\hline Abdominal pain & $461(26.9)$ & $2,864(15.7)$ & $<0.001$ \\
\hline Hyperlipidemia & $453(26.4)$ & $5,463(29.9)$ & 0.002 \\
\hline Headache & $324(18.9)$ & $2,495(13.7)$ & $<0.001$ \\
\hline Diabetes & $285(16.6)$ & $1,756(9.6)$ & $<0.001$ \\
\hline Asthma & $272(15.9)$ & $1,090(6.0)$ & $<0.001$ \\
\hline Fibromyalgia & $218(12.7)$ & $1,657(9.1)$ & $<0.001$ \\
\hline COPD & $175(10.2)$ & $626(3.4)$ & $<0.001$ \\
\hline Convulsions/seizures & $165(9.6)$ & $507(2.8)$ & $<0.001$ \\
\hline
\end{tabular}

aDetermined using Pearson's chi-square test.

$\mathrm{COPD}=$ chronic obstructive pulmonary disease.

TABLE 3 Prevalence of MS-Related Comorbidities

\begin{tabular}{|c|c|c|c|}
\hline & $\begin{array}{l}\text { Medicaid } \\
\text { n }(\%)\end{array}$ & $\begin{array}{l}\text { Commercial } \\
\mathrm{n}(\%)\end{array}$ & $P$ Value $^{\mathrm{a}}$ \\
\hline Overall, $\mathrm{n}$ & 1,715 & 18,269 & \\
\hline Asthenia & $497(29.0)$ & $5,110(28.0)$ & 0.374 \\
\hline $\begin{array}{l}\text { Dysesthesia (burning, } \\
\text { numbness, tingling sensations) }\end{array}$ & $375(21.9)$ & $3,203 \quad(17.5)$ & $<0.001$ \\
\hline Gait abnormality & $296(17.3)$ & $1,902(10.4)$ & $<0.001$ \\
\hline Urinary incontinence & $274(16.0)$ & $1,058 \quad(5.8)$ & $<0.001$ \\
\hline Dizziness/vertigo & $250(14.6)$ & $1,685 \quad(9.2)$ & $<0.001$ \\
\hline Muscle weakness & $194(11.3)$ & 1,527 & $<0.001$ \\
\hline
\end{tabular}

Lower pharmacy charges in the Medicaid group may be related to the overall lower use of disease-modifying treatments (DMTs) $-32.5 \%$ compared with $52.1 \%$ in the commercial group (Table 6). While self-injectable and oral product use was proportionally lower in the Medicaid group, the use of infused agents (e.g., natalizumab) was even lower. Although the proportion of patients receiving DMTs was lower in the Medicaid group, these patients received a greater number of prescriptions filled for DMTs during the year. This may suggest a greater adherence to therapy or at least a more consistent refill rate in those patients who received a prescription for a DMT.

\section{Discussion}

\section{Health Care Delivery}

Variances in health care delivery and utilization are affected by benefit design. This study provides a source of notable differences in health care utilization between commercially and publicly insured MS patients. These differences may be especially important regarding coordination of care and DMT use. Well-coordinated care is vital for those with chronic illnesses and those with multiple comorbid conditions, as in this 
Quantifying Differences in Health Care Consumption for the Management of

Multiple Sclerosis Within Privately and Publicly Insured Health Care Programs

\begin{tabular}{|c|c|c|c|c|c|c|c|}
\hline \multirow{2}{*}{$\begin{array}{l}\text { Service Category } \\
\text { Commercial Patients } \\
(\mathrm{n}=18,269) \\
\text { Medicaid Patients } \\
(\mathrm{n}=1,715)\end{array}$} & \multicolumn{2}{|c|}{ Percentage with Use } & \multicolumn{2}{|c|}{ Average Annual Charges } & \multicolumn{2}{|c|}{ Percentage of Total } & \multirow{2}{*}{$\begin{array}{c}P \text { Value } \\
\text { (Comparing } \\
\text { Charges) }\end{array}$} \\
\hline & Medicaid (\%) & Commercial (\%) & Medicaid (\$) & Commercial (\$) & Medicaid (\%) & Commercial (\%) & \\
\hline Inpatient & 7.5 & 3.6 & 3,521 & 689 & 10.6 & 2.2 & $<0.001$ \\
\hline Outpatient & 86.1 & 89.0 & 7,469 & 5,785 & 22.4 & 18.6 & 0.001 \\
\hline Emergency room & 21.5 & 6.7 & 1,519 & 319 & 4.6 & 1.0 & $<0.001$ \\
\hline Pharmacy & 67.7 & 76.7 & 20,835 & 24,314 & 62.5 & 78.2 & $<0.001$ \\
\hline Total costs & & & 33,344 & 31,107 & 100.0 & 100.0 & 0.031 \\
\hline
\end{tabular}

study; adults with chronic conditions who receive coordinated and easily accessible care have better outcomes and report higher levels of satisfaction with that care. ${ }^{15-18}$ Medicaid coverage, compared with other insurance types such as commercial insurance, has been associated with poorer access to preventive, acute, and follow-up care. ${ }^{19}$

Variances in treatment options may also affect disease progression, relapse, and the development of comorbid conditions, which can have a favorable or unfavorable effect on cost-effectiveness. ${ }^{20}$ Because patients seen primarily in ER settings are often sicker and are likely unknown to the physician treating them, these patients are at greater risk for complications, readmissions, medical errors, duplicate tests, and functional deterioration that may drive up costs considerably. ${ }^{15,16}$ In a survey by Shabas and Heffener (2005) of 92 MS patients enrolled in a Medicaid long-term managed plan, $32 \%$ of the patients were never seen by an MS specialist physician, and $18 \%$ of patients who had begun a course of prescribed MS medications were noncompliant at the time of the survey. ${ }^{16}$ In our study, inpatient and ER charges were as much as 5 times higher in the Medicaid group.

\section{DMT Accessibility and Adherence}

Common MS sequellae (i.e., fatigue, physical disability, cognitive dysfunction, and pain) are associated with considerably higher costs for MS-related health care and may greatly affect quality of life, employment, social functioning, and nursing home placement. ${ }^{21,22}$ Controlling these sequellae through DMT compliance and coordinated care may provide for better clinical and economic outcomes, including lower risk for MS-related hospitalizations and relapse and a better quality of life. ${ }^{15-18,23-25}$ Most patients with MS are covered by some form of health care insurance; however, plan designs and formulary restrictions can create access barriers for some patients. ${ }^{26}$ The compliant use of DMTs is a core component of MS treatment and has been shown to lower the risks for MS-related hospitalizations and disease relapse, slow the progression of disability, and reduce MS-related treatment costs. ${ }^{23-25}$ The 2014 Drug Trend Report found that Medicare and commercially insured clients experi- enced a similar upward trend in specialty therapy prescribing (11.5\% Medicaid; $12.9 \%$ commercial); however, a nonadherence rate of $23.0 \%$ among all patients with MS was identified. ${ }^{27}$

Our study found a significant difference in overall DMT use between the Medicaid and commercially insured groups (32.5\% vs. $52.1 \%$ ) but noted that a greater number of prescriptions for DMTs was filled in the Medicaid patient cohort. While a greater number of prescriptions filled may appear to indicate greater medication compliance, adherence issues are multifaceted and include lack of care continuity, lack of patient education and support, and long wait times (such as those encountered by patients who primarily rely on the ER for care). ${ }^{28,29}$ Filling a prescription does not necessarily mean that the medication was used correctly, timely, or at all. Some patients are challenged by the physical and psychological discomfort of injected or infused DMTs, experience intolerable side effects, or have insurance coverage that limits which DMTs may be prescribed, which limits the physician's ability to switch to other more tolerable DMTs. ${ }^{30}$

The Medicaid group of patients had greater ER and inpatient use along with significantly higher MS-related comorbidities, which may indicate poor coordination of care or a lack of patient education regarding the proper administration of DMTs. Coordinated management strategies that optimize a strong provider-patient relationship, patient communication and education, and positive reinforcement medication have a positive impact on DMT use and adherence among all patients with MS regardless of insurance provider type..$^{24,25,29}$

\section{Limitations}

There are 4 key limitations to our study. First, the data do not differentiate between MS-specific and comorbidity-related ER visits. Our analysis points out the much higher ER use among Medicaid-insured patients with MS compared with those who are commercially insured ( $21.5 \%$ vs. $6.7 \%)$, possibly indicating worse disease control and unmet needs. However, additional studies using differentiated data are needed to distinguish MS-specific from comorbidity-related ER visits. 


\section{TABLE 5 Facility Use by Group}

\begin{tabular}{|c|c|c|c|}
\hline Metric & $\begin{array}{l}\text { Medicaid } \\
\text { n (\%) }\end{array}$ & $\begin{array}{l}\text { Commercial } \\
\text { n (\%) }\end{array}$ & $P$ Value \\
\hline Overall, $\mathbf{n}$ & 1,715 & 18,269 & \\
\hline Single ER visit (per year) & $28(1.6)$ & $162(0.9)$ & $<0.001^{\mathrm{a}}$ \\
\hline Multiple ER visits & $341(19.9)$ & $1,068(5.8)$ & $<0.001^{\mathrm{a}}$ \\
\hline $\begin{array}{l}\text { Average number of ER visits } \\
\text { per year within the group }\end{array}$ & 16.1 & 10.7 & $<0.001^{b}$ \\
\hline $\begin{array}{l}\text { Single inpatient admission } \\
\text { (per year) }\end{array}$ & $90(5.2)$ & $236(1.3)$ & $<0.001^{\mathrm{a}}$ \\
\hline Multiple inpatient admissions & $30(1.7)$ & $52(0.3)$ & $<0.001^{\mathrm{a}}$ \\
\hline $\begin{array}{l}\text { Average number of inpatient } \\
\text { admissions per year within } \\
\text { the group }\end{array}$ & 1.3 & 1.4 & $0.641^{b}$ \\
\hline $\begin{array}{l}\text { Total length of stay per year } \\
\text { (in days) }\end{array}$ & 8.3 & 12.5 & $0.100^{b}$ \\
\hline \multicolumn{4}{|c|}{$\begin{array}{l}\text { aDetermined using Pearson's chi-square test. } \\
\text { betermined using Independent Samples T-test. } \\
\text { ER=emergency room. }\end{array}$} \\
\hline
\end{tabular}

Second, our data do not distinguish between MS-specific charges and comorbidity-related charges. MS-related symptoms and comorbidities, such as numbness and tingling, gait abnormalities, diabetes (that may result from reduced immobility leading to weight gain), urinary incontinence, and dizziness, occurred at higher rates among Medicaid-insured MS patients. These comorbidities may influence inpatient and ER use and can be presumed to add significantly to MS-related costs. Management strategies leading to a reduction in the frequency and severity of symptoms, relapse, or comorbid conditions requiring ER or inpatient care may have a substantial effect on the economic consequences of MS. ${ }^{31}$

A third limitation rests with the design of this study, which focused solely on an analysis of data. As such, patient-reported satisfaction regarding insurance coverage was not included. A 2012 study by Fenton et al. concluded that higher ER use resulted in lower patient satisfaction. ${ }^{32}$ Whether or not that would have been true in our study is not known. Satisfied patients are more adherent to their plan of care, which potentially results in improved disease control and less need for emergency care. ${ }^{32}$ Finally, because we did not interview patients, true compliance and adherence rates were not determined and, thus, remain unknown.

Further studies with analyses that control for patient demographics, comorbidities, and regional variation may help to substantiate our data findings in the charges, resource use, and use of DMTs among publicly and privately insured MS patients. Moreover, additional studies controlling for MS disease severity, copayments, and coinsurance may further our understanding of patient adherence. To avoid potential overcounting of the study populations, a more conservative future study algorithm should include only patients who (a) received at least 2 diagnoses of MS or (b) received 1 diagnosis of MS and receipt of a DMT. Finally, there is also the possibility that Medicaid patients use the ER in fundamentally different ways compared with those who are commercially insured.

\section{Conclusions}

Significant variances exist in the consumption of health care for the treatment of MS in patients enrolled in privately and publicly funded health insurance programs. These variances may have additional implications relating to outcomes specific to MS. Controlling the prevalence of key medical conditions and use of drug therapy to slow progression of disability and reduce relapse through coordinated, accessible health care delivery could have a measurable effect on economic and utilization measures.

\section{TABLE 6 Use of Disease-Modifying Treatments by Group}

\begin{tabular}{|c|c|c|c|c|c|c|c|c|}
\hline \multirow{3}{*}{$\begin{array}{l}\text { Drug/Drug Class } \\
\text { Overall use }\end{array}$} & \multicolumn{4}{|c|}{ Medicaid } & \multicolumn{3}{|c|}{ Commercial } & \multirow{3}{*}{$\begin{array}{c}\begin{array}{c}P \text { Value } \\
\text { (Comparing \%)a }\end{array} \\
<0.001\end{array}$} \\
\hline & \multicolumn{3}{|c|}{ n (\%) Rxs/Year } & \multirow{2}{*}{$\begin{array}{c}\text { Days Supply } \\
290.1 \\
\end{array}$} & \multicolumn{2}{|c|}{ n (\%) Rxs/Year } & \multirow{2}{*}{$\begin{array}{c}\text { Days Supply } \\
279.2\end{array}$} & \\
\hline & 558 & $(32.5)$ & 10.0 & & $9,523(52.1)$ & 8.7 & & \\
\hline Self-injected & 519 & $(30.3)$ & 9.8 & 284.2 & $8,044 \quad(44.0)$ & 8.4 & 277.1 & $<0.001$ \\
\hline IFN beta-la (IM) & 118 & $(6.9)$ & 10.2 & 288.1 & $1,974 \quad(10.8)$ & 8.4 & 282.9 & $<0.001$ \\
\hline IFN beta-la (SC) & 98 & $(5.7)$ & 9.7 & 267.7 & $1,675 \quad(9.2)$ & 8.5 & 265.5 & $<0.001$ \\
\hline IFN beta-lb & 60 & $(3.5)$ & 8.6 & 244.6 & $901 \quad(4.9)$ & 8.6 & 271.7 & 0.008 \\
\hline Glatiramer acetate & 277 & $(16.2)$ & 8.7 & 262.0 & $3,708 \quad(20.3)$ & 7.8 & 264.6 & $<0.001$ \\
\hline Infused & 17 & $(1.0)$ & 11.5 & 362.0 & $1,076 \quad(5.9)$ & 9.0 & 234.0 & $<0.001$ \\
\hline Natalizumab & 17 & $(1.0)$ & 11.5 & 362.0 & $(5.8)$ & 9.1 & 234.0 & $<0.001$ \\
\hline Mitoxantrone & & - & & - & $(0.0)$ & 2.6 & - & - \\
\hline Oral & 36 & $(2.1)$ & 9.0 & 261.4 & $(4.4)$ & 7.3 & 243.5 & $<0.001$ \\
\hline Fingolimod & 33 & $(1.9)$ & 9.7 & 281.8 & $(4.2)$ & 7.6 & 253.7 & $<0.001$ \\
\hline Teriflunomide & 3 & $(0.2)$ & 1.3 & 37.3 & $(0.2)$ & 1.5 & 44.9 & 0.617 \\
\hline
\end{tabular}




\section{Authors}

TERRIE LIVINGSTON, PharmD; MONICA FAY, PharmD, MBA; RAVI IYER, PhD; and WENDY WELLS, PharmD, Biogen, Weston, Massachusetts. MICHAEL W. PILL, PharmD, Havas Gemini, New York, New York.

AUTHOR CORRESPONDENCE: Terrie Livingston, PharmD, Biogen, 133 Boston Post Rd., Weston, MA 02493.

E-mail: terrie.livingston@biogen.com.

\section{DISCLOSURES}

Funding for this study was contributed by Biogen. The preparation, writing, revision, and approval of this manuscript were conducted in collaboration with Pill, who is employed by Havas Gemini. Livingston, Fay, and Wells are employed by and own stock in Biogen. Iyer was employed with Biogen at the time of the study.

Study concept and design were contributed by Livingston, Fay, and Iyer, along with Pill and Wells. Livingston, Fay, and Pill collected the data, along with Iyer and Wells. Data interpretation was performed by Livingston, Fay, and Iyer, along with Pill and Wells. The manuscript was written by Livingston, Fay, and Wells, along with Pill and Iyer, and revised by Fay, Wells, and Pill, along with Livingston and Iyer.

\section{REFERENCES}

1. Hauser SL, Goodkin DE. Multiple sclerosis and other demyelinating diseases. In: Braunwald E, Hauser SL, Kasper DL, Fauci AS, Kasper DL, eds. Harrison's Principles of Internal Medicine. New York: McGraw Hill; 2001:2452-61.

2. Ringold S, Lynn C, Glass RM. Multiple sclerosis. JAMA. 2006;296(23):2880.

3. National Multiple Sclerosis Society. Disease courses. Available at: http:// www.nationalmssociety.org/For-Professionals/Clinical-Care/About-MS/ Disease-Courses. Accessed October 5, 2016.

4. National Institute of Neurological Disorders and Stroke. Multiple sclerosis: hope through research. Available at: http://www.ninds.nih.gov/disorders/ multiple_sclerosis/detail_multiple_sclerosis.htm. Accessed October 5, 2016.

5. Zwibel HL, Smrtka J. Improving quality of life in multiple sclerosis: an unmet need. Am J Manag Care. 2011;17(Suppl 5):S139-45.

6. Asche CV, Singer ME, Jhaveri M, Chung H, Miller A. All-cause health care utilization and costs associated with newly diagnosed multiple sclerosis in the United States. J Manag Care Pharm. 2010;16(9):703-12. Available at: http://www.jmcp.org/doi/10.18553/jmcp.2010.16.9.703.

7. National Multiple Sclerosis Society. Who gets MS? (Epidemiology). Available at: http://www.nationalmssociety.org/What-is-MS/Who-Gets-MS. Accessed October 5, 2016

8. Campbell JD, Ghushchyan V, McQueen R, et al. Burden of multiple sclerosis on direct, indirect costs and quality of life: national U.S. estimates. Mult Scler Rel Disord. 2014;3(2):227-36.

9. Noseworthy JH, Lucchinetti C, Rodriguez M, Weinshenker BG. Multiple sclerosis. N Engl J Med. 2000;343(13):938-52.

10. Hutchinson M. Truly benign multiple sclerosis is rare: let's stop fooling ourselves-commentary. Mult Scler. 2012;18(1):15.

11. Agarwal S, Anderseck B, Van Asch P, et al. Early mobility impairment: bridging the communication gap between people with multiple sclerosis and their healthcare providers. Neurology. 2013;80(7 Suppl):Abstract P02.221. Available at: http://www.neurology.org/content/80/7_Supplement/P03.221. Accessed October 18, 2016.
12. Pike J, Jones E, Rajagopalen K, Piercy J, Anderson P. Social and economic burden of walking and mobility problems in multiple sclerosis. BMC Neurol. 2012;12:94.

13. Margolis JM, Fowler R, Johnson BH, Kassed CA, Kahler K. Diseasemodifying drug initiation patterns in commercially insured multiple sclerosis patients: a retrospective cohort study. BMC Neurol. 2011;11:122. Available at: www.biomedcentral.com/1471-2377/11/122. Accessed October 5, 2016.

14. Bainbridge JL. Economics of multiple sclerosis and its treatment. University of Tennessee Advanced Studies in Pharmacy: Proceedings. 2007;4(11): 330-33. Available at: http://www.utasip.com/files/articlefiles/pdf/ asip_4_1lp330_333.pdf. Accessed October 5, 2016.

15. Schoen C, Osborn R, Squires D, Doty M, Pierson R, Applebaum S New 2011 survey of patients with complex care needs in eleven countries finds that care is often poorly coordinated. Health Aff (Millwood). 2011;30(12):2437-48

16. Shabas D, Heffner M. Multiple sclerosis management for low-income minorities. Mult Scler. 2005;11(6):635-40.

17. Berwick DM, Hackbarth AD. Eliminating waste in U.S. health care. JAMA. 2012;307(14):1513-16.

18. Katon WJ, Lin EHB, Von Korff M, et al. Collaborative care for patients with depression and chronic illnesses. N Engl J Med. 2010;363(27):2611-20. Available at: http://www.nejm.org/doi/full/10.1056/NEJMoal003955\#t= article. Accessed October 5, 2016.

19. Priest JL, Cantrell CR, Fincham J, Cook CL, Burch SP. Quality of care associated with common chronic diseases in a 9-state Medicaid population utilizing claims data: an evaluation of medication and health acre use and costs. Popul Health Manag. 2011:14(1):43-54. Available at: https://www.ncbi. nlm.nih.gov/pmc/articles/PMC3128443/. Accessed October 5, 2016.

20. Tappenden P, McCabe C, Chilcott J, Simpson E, et al. Cost-effectiveness of disease-modifying therapies in the management of multiple sclerosis for the Medicare population. Value Health. 2009;12(5):657-65. Available at: http://www.valueinhealthjournal.com/article/S1098-3015(10)60727-9/pdf. Accessed October 5, 2016.

21. Carroll CA, Fairman KA, Lage MJ. Updated cost-of-care estimates for commercially insured patients with multiple sclerosis: retrospective observational analysis of medical and pharmacy claims data. BMC Health Serv Res. 2014;14:286. Available at: https://www.ncbi.nlm.nih.gov/pmc/articles/ PMC4118272\%. Accessed October 5, 2016.

22. Rainmundo K, Tian H, Zhou H, et al. Resource utilization, costs and treatment patterns of switching and discontinuing treatment of MS patients with high relapse activity. BMC Health Serv Res. 2013;13:131. Available at: https://www.ncbi.nlm.nih.gov/pmc/articles/PMC3626727/. Accessed October 5, 2016.

23. Coyle PK, Cohen BA, Leist T, et al. Therapy optimization in multiple sclerosis: a prospective observational study of therapy compliance and outcomes. BMC Neurol. 2014;14:49. Available at: https://www.ncbi.nlm.nih.gov/ pmc/articles/PMC3984676/. Accessed October 5, 2016.

24. Tan H, Yu J, Tabby D, Devries A, Singer J. Clinical and economic impact of a specialty care management program among patients with multiple sclerosis: a cohort study. Mult Scler. 2010;16(8):956-63. Available at: https://www. ncbi.nlm.nih.gov/pmc/articles/PMC2923414/. Accessed October 5, 2016

25. Minden S, Hoaglin D, Jureidini S, et al. Disease-modifying agents in the Sonya Slifka Longitudinal Multiple Sclerosis Study. Mult Scler. 2008;14(5):640-55.

26. Mathis AS, Owens GM. Implications for multiple sclerosis in the era of the affordable care act: the shifting managed care landscape. Am J Manag Care. 2014;20(11 Suppl):S242-53. Available at: http://www.ajmc.com/journals/supplement/2014/ACE020_Dec14_MS_CE/ACE020_Dec14_MS_CE_ Mathis_S242/. Accessed October 5, 2016.

27. Express Scripts. The Express Scripts 2014 drug trend report. March 2015. Available at: https://lab.express-scripts.com/lab/drug-trend-report/ previous-reports. Accessed October 5. 2016. 
28. Devonshire V, Lapierre Y, Macdonell R, et al. The Global Adherence Project (GAP): a multicenter observational study on adherence to diseasemodifying therapies in patients with relapsing-remitting multiple sclerosis. Eur J Neurology. 2011;18(1):69-77.

29. American College of Preventive Medicine. Medication adherence time tool: improving health outcomes. Available at: http://www.acpm. org/?MedAdhereTTProviders. Accessed October 5, 2016.

30. National Multiple Sclerosis Society. Adherence. Available at: www. nationalmssociety.org/Treating-MS/Medications/Adherence. Accessed October 5, 2016.
31. IMS Institute for Healthcare Informatics. Healthcare spending among privately insured individuals under age 65. February 2012. Available at: http://www.imshealth.com/files/web/IMSH\%20Institute/Reports/ Healthcare\%20Spending\%20Among\%20Age\%2065/IHII_Spending_Report. pdf. Accessed October 5, 2016.

32. Fenton JJ, Jerant AF, Bertakis KD, Franks P. The cost of satisfaction: a national study of patient satisfaction, health care utilization, expenditures, and mortality. Arch Intern Med. 2012;172(5):405-11. Available at: http:// archinte.jamanetwork.com/article.aspx?articleid=1108766. Accessed October 5, 2016. 
Quantifying Differences in Health Care Consumption for the Management of

Multiple Sclerosis Within Privately and Publicly Insured Health Care Programs

\section{APPENDIX Summary of MS-Specific Disease Model}

A comprehensive Multiple Sclerosis Disease Benchmarks Disease Model was developed in advance of this study. It consisted of detailed, written specifications of metrics and substrata that (a) are applied to the source data (whether or not the data are first processed through episode-creating software) and (b) organize, stratify, and segment the source data into unique, disease-specific economic benchmarks of health care costs, units of use, and services utilized in the analysis, such as the following:

- Patient demographics (age, gender, geographic region)

- Markers of disease severity, including the presence and number of complications and comorbidities

- Patterns of pharmacotherapy (e.g., the prescription drugs used)

- Utilization of ancillary services (e.g., diagnostic and laboratory services, surgical procedures)

- Payer mix (commercial, self-insured, Medicare Advantage, and managed Medicaid)

- Episode costs and resource utilization across all health care service categories (inpatient care, outpatient care, emergency department, pharmacy)

The Disease Benchmarks Disease Model process eliminates the weaknesses of standard disease-specific data analysis and provides 2 critically important features:

- The structure and refinement upon which the data is pulled and the analyses conducted

- A roadmap for anyone who is creating the analytics and/or using the results of the analyses as to how and why the data were organized and what was done to yield the results being presented 